\title{
Forecasting the distribution of a range-expanding bat reveals future response to climate change and habitat
}

\author{
Michael C. True ${ }^{1,4}$, Roger W. Perry ${ }^{2}$, and William M. Ford ${ }^{3}$ \\ ${ }^{1}$ Department of Fish and Wildlife Conservation, Virginia Polytechnic Institute and State University, Blacksburg, VA, 24061, USA \\ ${ }^{2}$ U.S. Forest Service, Southern Research Station, Hot Springs, AR, 71902, USA \\ ${ }^{3}$ U.S. Geological Survey, Virginia Cooperative Fish and Wildlife Research Unit, Blacksburg, VA, 24061, USA \\ ${ }^{4}$ Corresponding author: E-mail: mtrue@vt.edu
}

\begin{abstract}
Many terrestrial vertebrate species are exhibiting geographic distribution changes including poleward range limit shifts in response to increases in regional temperature. Bats are a highly mobile taxa capable of rapid responses to changes in abiotic or biotic conditions. In North America, recent extralimital records of the non-hibernating Lasiurus seminolus (Seminole bat) have been attributed to climate change, however such attributions remain speculative and potentially subject to sampling bias in the form of increased recent sampling efforts at latitudes north of the historical range. We used historical occurrence records and simple environmental variables within a Maxent modeling framework to model the historical distribution of suitable areas for this species. We transferred the model using near current environmental conditions and measured the ability of the model to capture the apparent expansion in distribution using recent extralimital occurrence records. Our model transferred well over time concluding that the distribution expansion may be largely attributed to increasing minimum temperatures. We used the model to forecast the expansion in distribution of suitable areas at three 20-year intervals and various climate change scenarios and provide extrapolation risk maps for each scenario. Although increasing temperatures may increase potentially occupiable areas, the species is associated with forests and often roosts in pines (Pinus spp.). This suitable habitat is more limited to the northwest of the species' range, which may constrain the future species expansion despite favorable temperatures. We demonstrated this effect by mapping limiting factors through future climate change scenarios. We discovered a broad shift of effects that constrained the distribution from minimum temperature to an abundance metric of evergreen cover type as time and climate change intensity increased. Although uncertainties exist, we predict further expansion of the Seminole bat widely over the next 60 years across the eastern United States where suitable habitat and climate conditions converge. Our results appear consistent with other bat species showing similar range extensions and in turn provide further evidence that bats may serve as bioindicators of global change.
\end{abstract}

Key words: climate change, distribution expansion, Lasiurus seminolus, limiting factors, Maxent, Pinus spp., species distribution modeling

\section{INTRODUCTION}

The geographic distribution of a species is driven in part by abiotic tolerances in environmental space (Grinnell, 1917; Andrewartha and Birch, 1954; Franklin, 2009; Peterson, 2011). Temperature is often a large driver of distributions because ambient conditions relate directly to intrinsic requirements such as thermal regulation, reproduction, and water balance; these conditions also affect distributions indirectly by affecting extrinsic requirements such as food availability, cover, and other habitat resources needed for survival and reproduction (Araújo et al., 2005). Therefore, broad-scale environmental change, such as a warming climate, has or will result in poleward expansion in geographic distribution or increased latitudinal limits for many species (Parmesan, 2006). To date, these effects have been observed in highly mobile species including butterflies (Dennis, 1993; Parmesan et al., 1999; $\mathrm{Au}$ and Bonebrake, 2019), birds (Thomas and Lennon, 1999; Brommer, 2004; Hitch and Leberg, 2007; Massimino et al., 2015), and bats (Sachanowicz et al., 2006; Lundy et al., 2010; Ancillotto et al., 2016; Wu, 2016; McCracken et al., 2018; Perry, 2018; Hintze et al., 2019). All these taxa are volant, with substantial dispersal abilities, and therefore have a greater capacity to change their geographic positioning in response to abiotic stimuli compared to less mobile taxonomic groups.

In temperate regions, temperatures fluctuate widely by season. Therefore, bats must position 
themselves in thermally suitable regions for reproductive and energetic demands (Lyman, 1970). To account for decreased temperatures in the winter months, bats either hibernate or migrate, depending on the species (Fleming, 2019). For non-hibernating bats, increased temperatures earlier in the spring may result in early migration, increased foraging opportunities, and a longer period to establish maternity sites (Sherwin et al., 2012). These effects, plus their ability to fly long distances, may result in poleward expansion of temperate bats in response to increasing annual temperatures if other necessary resources are available (Sherwin et al., 2012).

In North America, bats have received unprecedented attention in response to the introduction of Pseudogymnoascus destructans (Pd), the fungal agent that causes White Nose Syndrome (WNS Lorch et al., 2011). This disease is responsible for the population collapse of some cave-hibernating species (Frick et al., 2015). WNS has led to increased bat survey and conservation efforts in the eastern United States and has highlighted current biogeographic trends for both impacted and non-impacted bat species. For example, numerous extralimital records of Tadarida brasiliensis (Brazilian free-tailed bat - Genoways et al., 2000; Ommundsen et al., 2017; McCracken et al., 2018), and Lasiurus seminolus (Seminole bat - Mcallister et al., 2004; Lacki et al., 2014; Perry, 2018) have been observed. However, attributing apparent expansions in range for species and communities based solely on climate change may be misleading because other factors may be contributory (Abrams and Nowacki, 2015, 2019; Razgour et al., 2016). For bats, habitat factors (Ford et al., 2005; Carter, 2006; Lundy et al., 2010; Razgour et al., 2016) or niche vacancies as a result of WNS (Jachowski et al., 2014) that are not necessarily tied to climate per se can shape local and regional distribution patterns. Also, temporally biased detection may suggest apparent range expansion when the species already occurred in extralimital localities but previously went undetected (Razgour et al., 2016).

Our study expands upon Perry (2018), who initially investigated the range expansion of L. seminolus. County-level occurrence records indicated a range limit shift approximately $500 \mathrm{~km}$ northward and $200 \mathrm{~km}$ westward during the past 50 years. Although useful for informing managers about L. seminolus detections in previously unknown localities, primary drivers of this expansion and their mechanisms and patterns remain speculative. Additionally, limiting the occupiable regions based solely on localities where the species is detected may fail to reveal the full extent of their current and future occupancy. Recent L. seminolus captures by the authors along the mid-Atlantic Coast may provide support for northward expansion into localities not documented previously in Perry (2018). Herein, we used county-level occurrence records, with dates predating consistent regional warming trends to model the historical distribution of $L$. seminolus to understand drivers (such as climate and landscape) using a species distribution model (Franklin, 2009; Peterson, 2011). Then, we transferred the model into near-current conditions to validate recent expansions in distribution and attributed these expansions to changes in model variable values. We then forecasted the distribution of suitable areas for L. seminolus in future 20-year intervals under a range of climate and landscape change scenarios. We hypothesized that 1) the distribution (and recent expansion in distribution) of L. seminolus would be mediated both by minimum temperatures and presence of pine forest cover, and that 2) the future potential distribution will expand in a manner consistent with changes in these environmental factors.

\section{Materials AND Methods}

\section{Occurrence Data}

To model the distribution of $L$. seminolus, we used the widely applied maximum entropy form of species distribution modeling (Maxent - Phillips et al., 2006). Maxent requires 'presence-only' data as occurrence points and then generates a random selection or user-based selection of 'background' points as absence points (referred sometimes as 'pseudoabsences' - Elith et al., 2011; Merow et al., 2013). To populate the model, we obtained all $L$. seminolus occurrence records that appear in Perry (2018). These records were based on visual identification to species such that the species was either captured (via mist-netting), existed in a museum collection or, rarely, recorded as a carcass (e.g., at a telecommunication tower). The records were obtained via 33 museums, 19 individuals and organizations, and 38 publications (Supplementary Data SD1-3 in Perry [2018]). We also obtained georeferenced records from the Global Biodiversity Information Facility (GBIF, see www.GBIF.org, accessed 11 May 2020) from the years 1935 to 2019 , additional capture data from a state wildlife agency from 2006 to 2019, and mist-net captures by the authors in 2019. Most records were referenced by year, month, and United States county only. Therefore, throughout, we used the county averages of each variable as our level of resolution for model building, testing, and projection. We recognize the reduced precision and overfitting risk by using models at this resolution; however, Collins et al. (2017) demonstrated that counties in the eastern United States are generally small and homogenous with respect to physiographic province/ecological type and overfitting effects therefore are limited, particularly when the sample size of occurrence records are large (i.e. $n>100$ ). 
We filtered L. seminolus occurrence records into two temporal groups for use in model calibration and independent temporal transferability testing. Temporal transferability testing refers to measuring the accuracy of a model calibrated using historical data in estimating the species distribution in a different time period (Randin et al., 2006; Huang et al., 2016). We selected 1935 through 1984 (50 years) and 2000 through 2019 (20 years) as historical and recent periods, respectively. We chose these periods because 1) county records predating 1935 are almost entirely accounted for in our historical period; 2) reducing the time range better reflects the climate and habitat conditions experienced by L. seminolus; 3 ) number of unique county records in each time step is approximately equal ( $n=121$ and $n=133$, respectively) and 4) the end of 1984 is when regional annual temperatures began to deviate from normal in the southeastern region of the United States (National Oceanic and Atmospheric Administration, https:/www.ncdc.noaa.gov/cag/regional/timeseries). The 2000 through 2019 period served as an appropriate interval for the recent group because future projections from the 6th phase of the Coupled Model Intercomparison Project (CMIP6 - Eyring et al. 2016) accessed through WorldClim (WorldClim ver. 2.1 - see worldclim.org, accessed 23 May, 2020) are on a 20-year scale (2021-2040, 2041-2060, 20612080).

Perry (2018) noted a small number of 'outlier' records of L. seminolus at localities well beyond the geographic range. These records were recorded exclusively during the autumnal season (August through November) and are assumed vagrant individuals (i.e., through migration or juvenile dispersal) and therefore non-residents for the active season (April through November). As such, these localities do not provide indication of the environments experienced by the species throughout the entire active season and therefore we did not include in our modeling of the active-season distribution. However, as shown in range maps by Perry (2018), some outlier records do occur just beyond the range limit of the species and could be an indication of range shift. Therefore, we chose a cutoff of $150 \mathrm{~km}$ beyond the edge of range maps in Perry (2018) for excluding these records in our models. This resulted in the exclusion of two county records (Thompson Co., NY and Lancaster Co., PA) in the 1935-1984 period and three county records (Milwaukee Co., WI, Val Verde Co., TX, and Kiowa Co., OK) in the 2000 2019 period (Fig. 1). An additional record (Fayette Co., KY) was not included as the bat carcass was found in a parking garage which may suggest vehicular transport.

\section{Climatic and Landscape Variables}

We selected seven landscape and climatic variables to model L. seminolus distribution (Table 1). We obtained historical (1935-1984) and recent (2000-2019) climatic variables that consisted of monthly gridded $(4-\mathrm{km})$ variables of minimum temperature $\left({ }^{\circ} \mathrm{C}\right)$, maximum temperature $\left({ }^{\circ} \mathrm{C}\right)$, mean temperature $\left({ }^{\circ} \mathrm{C}\right)$, and precipitation $(\mathrm{mm})$ from the PRISM Climate Group (prism.oregonstate.edu, accessed 21 May 2020) using the R (R Core Team, 2019) package 'prism' (Hart and Bell, 2015). We obtained modelled future projections of the same variables from all available climate modeling groups contributing to CMIP6 (Table 1 and Supplementary Appendix S1) that are available through WorldClim (worldclim.org, accessed 23 May, 2020). We downloaded these gridded (0.5-minute) variables for the time periods 2021-2040, 2041-2060, and 2061-2080 from Shared Socio-economic Pathways (SSPs - Table 2) of 2, 3, and 5 (O’Neill et al., 2014). These pathways were paired with Representative Concentration Pathways (RCPs - Table 2) of greenhouse gases of $4.5,7.0$, and $8.5 \mathrm{~W} / \mathrm{m} 2$ radiative force, respectively (van Vuuren et al., 2011). These SSP scenarios
$1935-1984$

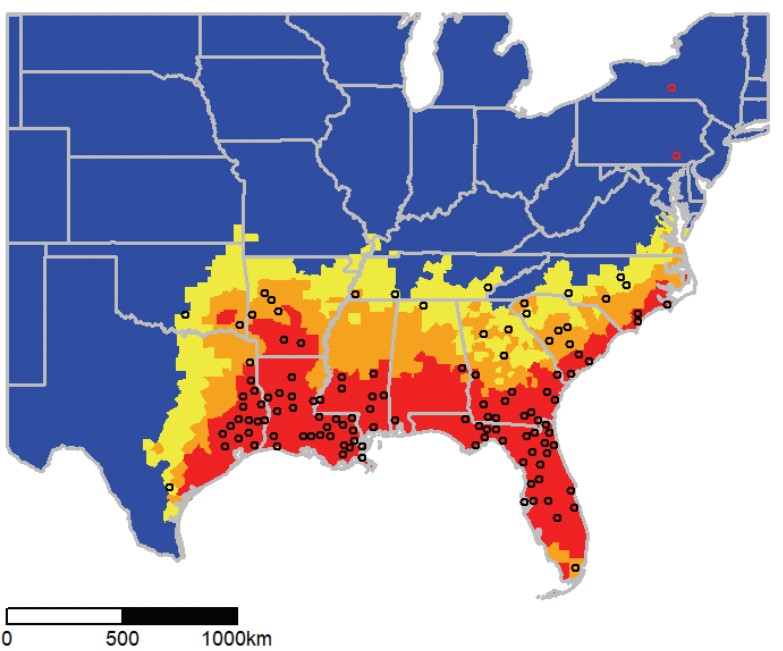

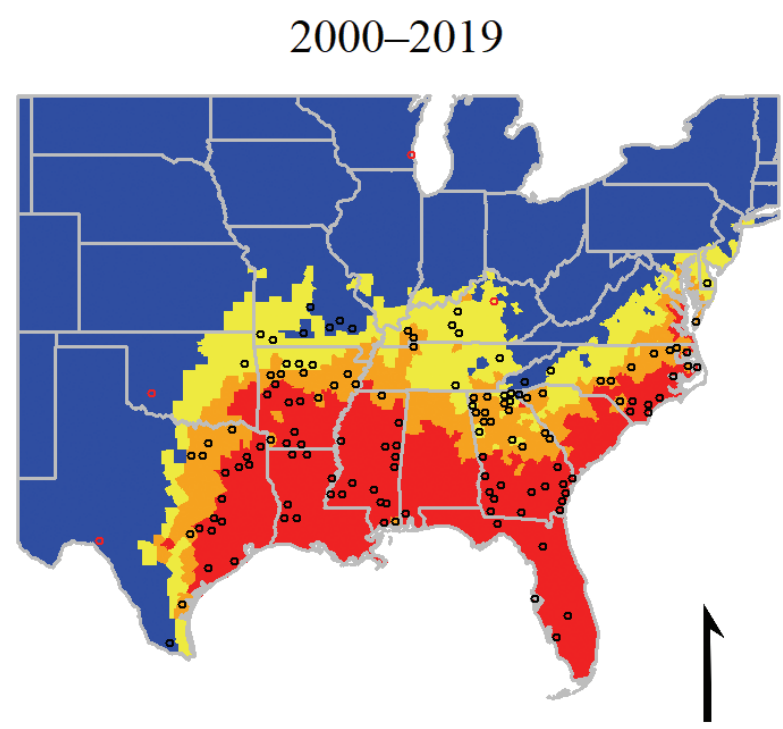

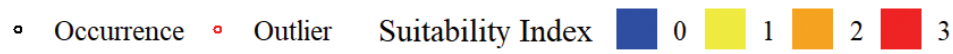

FIG. 1. Geographic distribution of county-level suitability indices for L. seminolus in the periods 1935-1984 and 2000-2019. Maps indicate binned suitability indices (0-3) calculated using sensitivity thresholds of the temporally independent 2000-2019 group. Open circles indicate U.S. county centroids of county-level occurrence records in each time period. Red open circles indicate outlier records described in text and in Perry (2018), which were not included in the modelling process, whereas black open circles indicate occurrence records documented either in the known geographic range (Perry, 2018) or during the summer maternity period 
TABLE 1. Descriptions of variables used in L. seminolus distribution modeling, 1935-1984 and 2000-2019. Variable values were averaged within United States counties. Data sources are listed by variable and period and described in detail in text

\begin{tabular}{|c|c|c|c|c|c|}
\hline \multirow[b]{2}{*}{ Variable } & \multirow[b]{2}{*}{ Description } & \multirow[b]{2}{*}{ Resolution } & \multicolumn{3}{|c|}{ Period \& Data source } \\
\hline & & & 1935-1984 & 2000-2019 & $\begin{array}{l}2021-2040 \\
2041-2060 \\
2061-2080\end{array}$ \\
\hline Temperature maximum ${ }^{1}$ & $\begin{array}{l}\text { Average maximum temperature }\left(\mathrm{C}^{\circ}\right) \text { averaged } \\
\text { over the active season (April-November) and } \\
\text { over the period }\end{array}$ & U.S. county & PRISM & PRISM & $\begin{array}{l}\text { CMIP6 } \\
\text { GCMs } \\
\text { (WorldClim) }\end{array}$ \\
\hline Temperature minimum ${ }^{1,2}$ & $\begin{array}{l}\text { Average minimum temperature }\left(\mathrm{C}^{\circ}\right) \text { averaged } \\
\text { over the active season (April-November) } \\
\text { and over the period }\end{array}$ & U.S. county & PRISM & PRISM & $\begin{array}{l}\text { CMIP6 } \\
\text { GCMs } \\
\text { (WorldClim) }\end{array}$ \\
\hline Temperature mean ${ }^{1}$ & $\begin{array}{l}\text { Average temperature }\left(\mathrm{C}^{\circ}\right) \text { averaged over the } \\
\text { active season (April-November) and over the } \\
\text { period }\end{array}$ & U.S. county & PRISM & PRISM & $\begin{array}{l}\text { CMIP6 } \\
\text { GCMs } \\
\text { (WorldClim) }\end{array}$ \\
\hline Precipitation $(\mathrm{mm})^{1,2}$ & $\begin{array}{l}\text { Average precipitation }(\mathrm{mm}) \text { averaged over the } \\
\text { active season (April-November) and over the } \\
\text { period }\end{array}$ & U.S. county & PRISM & PRISM & $\begin{array}{l}\text { CMIP6 } \\
\text { GCMs } \\
\text { (WorldClim) }\end{array}$ \\
\hline $\begin{array}{l}\text { Proportion of year } \\
>4^{\circ} \mathrm{C} 1\end{array}$ & $\begin{array}{l}\text { Average proportion of year }>4^{\circ} \mathrm{C} \text { through } \\
\text { period }\end{array}$ & U.S. county & PRISM & PRISM & $\begin{array}{l}\text { CMIP6 } \\
\text { GCMs } \\
\text { (WorldClim) }\end{array}$ \\
\hline Seasonality ${ }^{1,2}$ & $\begin{array}{l}\text { Standard deviation of monthly mean } \\
\text { temperatures over period }\end{array}$ & U.S. county & PRISM & PRISM & $\begin{array}{l}\text { CMIP6 } \\
\text { GCMs } \\
\text { (WorldClim) }\end{array}$ \\
\hline $\begin{array}{l}\text { Mixed/Evergreen } \\
\text { forest cover }{ }^{1,2}\end{array}$ & $\begin{array}{l}\text { Percent county coverage of evergreen or } \\
\text { mixed evergreen and deciduous forest }\end{array}$ & U.S. county & $\begin{array}{l}\text { USGS } \\
\text { CONUS } \\
\text { Backcasting }\end{array}$ & $\begin{array}{l}\text { USGS } \\
\text { CONUS } \\
\text { NLCD }\end{array}$ & $\begin{array}{l}\text { USGS } \\
\text { CONUS } \\
\text { Future }\end{array}$ \\
\hline
\end{tabular}

1 - Variables used in set 1 - all created or available variables;

2 _ Variables used in set 2 — variables remaining after removal of highly correlated variables (Pearson's correlation coefficient $<0.85$ )

(which are paired with RCPs - Table 2) are modelled simulations that result in varying global temperature increases by 2100 $\left(\mathrm{SSP} 2[\mathrm{RCP} 4.5]=3.8-4.2^{\circ} \mathrm{C}, \mathrm{SSP} 3[\mathrm{RCP} 7.0]=3.9-4.6^{\circ} \mathrm{C}\right.$, SSP 5 [RCP 8.5] $=4.7-5.1^{\circ} \mathrm{C}$ - Table 2; O'Neill et al., 2014). We chose SSP 2 (RCP 4.5), SSP 3 (RCP 7.0), and SSP 5 (RCP $8.5)$ as they consisted of three of the four available scenarios through WorldClim. We did not include SSP 1 (RCP 2.6) as this scenario involves a global consensus toward sustainability and green energy; therefore, it suggests a relatively minimal temperature increase. As such, we were more interested in scenarios with greater temperature anomalies that are similar to or exceed the current global trends.

For each period and SSP, we averaged all above climatic variables across climate model outputs, then averaged each climatic variable over months that $L$. seminolus are most active across their entire distribution (April through November Perry, 2018). To account for seasonal effects on the distribution (Lundy et al, 2010), we created a seasonality variable calculated as the standard deviation of temperature means for each period and averaged for each county. We also created a potentially relevant variable that calculated the annual proportion of time whereby temperatures are above $4^{\circ} \mathrm{C}$ because L seminolus are most active above that temperature threshold (Hein et al., 2008).

Lasiurus seminolus actively select large overstory Pinus spp. (pines) as day-roosts throughout their distribution (Menzel et al., 1998, 1999, 2000; Hein et al., 2005, 2008; Perry and Thill, 2007; Perry, 2018). To account for this in the modelling process, we retrieved past (Sohl et al., 2016), recent (Yang et al., 2018), and future projections (Sohl et al., 2014) of contiguous
United States land use and land cover (LULC) data that included Pinus spp. coverage from the United States Geological Survey (USGS, https://www.usgs.gov/land-resources/eros/lulc/ data-tools, accessed 24 May, 2020), selecting the years 1960, 2008, 2030, 2050, and 2070 as closest available median years for each period. Because modeled future landcover scenarios (Sohl et al., 2014) use the now obsolete IPCC climate change scenarios (Nakićenović et al., 2000), we used similar carbon emission and warming scenarios A2, B2, and B1 in LULC model forecasts (Sohl et al., 2014) as analogs to SSP 2 (RCP 4.5), SSP 3 (RCP 7.0), and SSP 5 (RCP 8.5), respectively (see O'Neill et al. (2014) and van Vuuren et al. (2011) for full descriptions]. For all LULC datasets covering each period, we converted LULC cover data to a binary format such that cells containing mixed deciduous-evergreen or evergreen forest as a surrogate for Pinus spp. cover with values equal one and all else equal zero. We averaged these binary raster layers over United States county boundaries effectively created a coarse metric of potential roost availability in the form of percent coverage of mixed or evergreen forest cover type at the county grain.

\section{Maxent Modeling}

A critical decision component with Maxent is defining the geographical extent used to extract background points, with the assumption that all background points are accessible to the species in question (Elith et al., 2011). We considered aberrant outlier records (Perry, 2018) as indicators of L. seminolus dispersal ability. Therefore, we cropped all input raster data two 
TABLE 2. Names, and descriptions of climate change related terms used in L. seminolus distribution modeling

\begin{tabular}{|c|c|c|c|}
\hline Term & Full name & Description & Source \\
\hline CMIP & $\begin{array}{l}\text { Coupled Model } \\
\text { Intercomparison } \\
\text { Project }\end{array}$ & $\begin{array}{l}\text { Headed by the World Climate Research Program, CMIP is an } \\
\text { international collaboration of } 30+\text { groups each providing climate } \\
\text { models under future economic, socio-political, and greenhouse } \\
\text { gas emissions scenarios for use in collaboration. CMIP6 is the most } \\
\text { recent phase of the project in which climate is forecasted into the } \\
\text { future under certain pairings of shared socioeconomic pathways } \\
\text { (SSPs) and Representative Concentration Pathways (RCPs) }\end{array}$ & Eyring et al. (2016) \\
\hline SSP & $\begin{array}{l}\text { Shared Socio-economic } \\
\text { Pathway }\end{array}$ & $\begin{array}{l}\text { SSPs are integrated scenarios that incorporate both climate change } \\
\text { and policy decisions across the globe. Various designations of SSPs } \\
(1-5) \text { describe the level of socio-economic challenges for adaptation } \\
\text { to and mitigation of climate change. In this paper, we use SSP-2, } \\
\text { SSP-4, and SSP- } 5 \text { which are paired with the RCPs below for our } \\
\text { future outputs }\end{array}$ & O’Neill et al. (2014) \\
\hline $\mathrm{RCP}$ & $\begin{array}{l}\text { Representative } \\
\text { Concentration Pathway }\end{array}$ & $\begin{array}{l}\text { RCPs are pathways that describe radiative forcing (i.e. the difference } \\
\text { in solar irradiance absorbed and radiated by Earth) projected to occur } \\
\text { by } 2100 \text {. Four pathways are commonly used in climate modeling and } \\
\text { incorporated in CMIP } 6-2.6,4.5,7.0 \text {, and } 8.5 \mathrm{~W} / \mathrm{m} 2 \text {. In this } \\
\text { paper we use RCP } 4.5 \text {, RCP } 7.0 \text {, and RCP } 8.5 \text { which are paired } \\
\text { with the SSPs above for our future outputs }\end{array}$ & van Vuuren et al. (2011) \\
\hline
\end{tabular}

degrees beyond the minimum and maximum occurrence latitude and 3.5 degrees beyond minimum and maximum occurrence longitudes. To calibrate the model, we used county-level historical $(1935-1984)$ occurrence records $(n=121)$ as presences, and all remaining counties in the extent as background $(n=2428)$. These data were geographically partitioned into four approximately equal blocks, partitioned by longitude and latitude (Muscarella et al., 2014), using opposite, diagonal blocks as testing and training groups. We used two variable sets in the modeling process: set 1 contained all variables $(n=7)$ and set 2 contained a subset of those variables whereby we omitted highly correlated variables (Pearson correlation coefficient, $r>0.85, n=4$ - Table 1) as to provide two comparable sets one to include as many variables that may influence the distribution as possible and one that is more parsimonious, yet retains the general trends of the other variables.

During parameter estimation, Maxent uses singular or combined 'features' (linear, quadratic, threshold, and hinge) to estimate relationships between occurrence/background and each predictor variable. Additionally, a regularization multiplier is used to control fitting (see Elith et al., 2011). Because appropriate settings are inherently unknown and can lead to inaccuracies when using default settings (Merow et al., 2013), we used the R package ENMeval (Muscarella et al., 2014) to produce models of all possible unique combinations of features and regularization multipliers. We used regularization multipliers of 0.1 , $0.5,0.75,1-10$, and 12 , and combinations of features classes 'L', 'LQ', 'H', 'LQH', 'LQHP', 'LQHPT' (where L = linear, $\mathrm{Q}=$ quadratic, $\mathrm{H}=$ hinge, $\mathrm{P}=$ product, and $\mathrm{T}=$ threshold features - Muscarella et al., 2014). With each unique feature-regularization multiplier combination, we trained the model and then validated it using the test group; we then reversed the process with the training group becoming the testing group.

We retained models with an average test area under the receiver operating characteristic (ROC) curve $>0.9$ (AUCTEST - Hanley and McNeil, 1982; Peterson, 2011), average test 10\% omission rate $<0.11$ (OR10 - Fielding and Bell, 1997; Peterson, 2011), average minimum training presence omission rate
$<0.01$ (ORMTP — Fielding and Bell, 1997; Peterson, 2011), and average train and test AUC difference $<0.01$ (AUCDIFF Warren and Seifert, 2011; for complete descriptions of all metrics see Muscarella et al., 2014). We then used the minimum small-sample corrected Akaike's Information Criterion (AICc - Burnham and Anderson, 2004) for selecting the final top-approximating model. Upon final model selection, we ran a jackknife test for each selected variable, resulting in a measure of percent variable contribution (Hijmans et al., 2020).

\section{Temporal Transferability and Suitability Indices}

We used the model and period-specific environmental variables to estimate the relative occurrence rate of $L$. seminolus for both historical (1935-1984) and recent (2000-2019) periods and measured the predictive performance of the model transfer to the latter time period. Measures of AUC are often misleading in presence-only applications due to background points that do not represent true absences (Peterson et al., 2008). To place emphasis on the true positive rate (sensitivity), we measured the AUC ratio of the partial ROC (Error $=0.05$, replications $=$ $1000)$ from the 2000-2019 county occurrences $(n=133)$ and background counties $(n=2416)$. An AUC ratio equal to one indicates no better than random, whereas an AUC ratio equal to two is perfect discrimination between occurrence and background. An AUC ratio between one and two would indicate fair temporal transferability (Peterson et al., 2008).

Maxent defaults to logistic output $(0-1)$ to estimate the geographic distribution relative occurrence rate (Merow et al., 2013). Although thresholding relative occurrence rates can be relatively arbitrary (Merow et al., 2013), assigning suitability indices increases ease of visualizing change across time periods. We converted the continuous relative occurrence rate to categorical suitability indices using the 2000-2019 period sensitivity measures of $0.95-1$ as unsuitable (suitability index $=0$ ), 0.80 to $<0.95$ as occupiable (suitability score $=1$ ), 0.5 to $<0.80$ as suitable (suitability index $=2$ ), and $<0.5$ as highly suitable (suitability index $=3$ ). 
Past, Current and Future Projections, Extrapolation Risk, and Limiting Factors

We deemed suitability indices appropriate for all future projections because we were estimating regions that were potentially occupiable as opposed to the realized distribution of L. seminolus. We used our model to estimate the relative occurrence rates on historical (1935-1984), recent (2000-2019), and future (2021-2040, 2041-2060, 2061-2080 - SSP 2, SSP 3, SSP 5) intervals, using relevant climatic and landscape data in R package dismo (Hijmans et al., 2020). We converted each relative occurrence rate map to the above suitability indices and geographically mapped each.

Future suitability projections are inherently uncertain and extrapolating to new time periods or geographic regions can be risky (Elith et al., 2010; Mesgaran et al., 2014). MaxEnt distribution models are built on fixed correlations of variables in model calibration; therefore, if colinear shift occurs, the model becomes less useful as transferability decreases (Elith et al., 2010; Mesgaran et al., 2014). To highlight areas of extrapolation risk in our context, we used two detection methods for environmental novelty introduced by Mesgaran et al. (2014) as Type 1 (NT1) and Type 2 (NT2). The NT1 identifies geographic areas that are novel due to covariate values outside the range of individual training variables. The NT2 identifies geographic areas within the range of individual variables but quantifies degree of novelty between covariates (Mesgaran et al., 2014). The NT1 values less than zero indicate areas outside the univariate range, whereas NT2 values between zero and one indicate relatively similar yet increasing degree of novelty as the value approaches one. We calculated NT1 and NT2 values for each future projection and mapped each geographically. Lastly, using methods provided by Elith et al. (2010), we calculated and mapped the limiting factors, defined as the Maxent variable most influential in the estimated relative occurrence rate, for each future relative occurrence rate estimation.

\section{RESULTS}

A full run of all possible regularization multipliers, features, and variable sets resulted in 168 Maxent candidate models. After filtering based on model predictive performance, 43 candidate models remained, whereby all of which contained the reduced set 1 variables (Table 1). Our top-supported model showed that minimum temperature was a major contributor (ca. $50 \%$ ), followed by presence of mixed/evergreen forest cover (ca. 29\%), and precipitation (ca. 19\%) in permutation contribution. Overall seasonality effects were negligible. Background-occurrence associations with minimum temperature, mixed/evergreen forest cover, and precipitation were positive. The AUC ratio transferability test resulted in a measure of 1.44 , indicating moderate temporal transferability (Peterson et al., 2008).

Using 2000-2019 occurrence data, the sensitivity ranges of $>0.95-1,>0.8-0.95,>0.5-0.8$, and $<0.5$ for a threshold at Maxent's logistic output (relative occurrence rate) ranges of $0-0.031$, $>0.031-0.114,>0.114-0.315$, and $>0.315$ respectively were returned, whereby we labeled suitability indices as not suitable (0), occupiable (1), suitable (2), and highly suitable (3). Estimations of the relative occurrence rate, reclassified as suitability indices for the 1935-1984 and 2000-2019 intervals, indicated an expansion of suitability in geographic area in the latter period (Fig. 1). Within the extent, average relative occurrence rate of $L$. seminolus increased from near 0.13 to near 0.17 between the two periods, signifying a general increase and expansion of suitable areas. The change between periods also resulted in a general increase in geographic expanse (sum of county areas) of occupiable area (suitability indices $1-3)$ by approximately $372,189 \mathrm{~km}^{2}$. The average geographic shift in occupiable areas (suitability index 1) increased by $196 \mathrm{~km}$ northward and $56.6 \mathrm{~km}$ westward.

Modelled suitability forecasts for future climatic and landscape scenarios revealed a continued increase in areas suitable for occupancy by L. seminolus (Fig. 2). These increases were most pronounced under the most temporally distant and extreme scenarios (2061-2080 - SSP 5; Fig. 2). The average relative occurrence rate throughout the extent continually increased in each future period generally with between-SSP averages of $0.22,0.29,0.37$, signifying potential future expansion of the species distribution. Additionally, the standard deviation of average relative occurrence rate of within-period SSPs continually increased, signifying increased uncertainty as periods become more distant. Nevertheless, expansion was evident, particularly in the Midwest states of Kentucky and Missouri and along the mid-Atlantic Coast states of Virginia, Maryland, and Delaware.

Considering extrapolation risk, we did not find any future climate scenarios whereby NT2 values were $>1$, signifying minimal colinear shift; however, in more southernly regions, NT1 values appeared as minimum temperature values were above values in the training set (Fig. 3). This becomes increasingly apparent at distant time periods and larger temperature anomalies (increased SSP levels). The NT2 values generally increased across the entire extent as time and SSP levels increased, predominately in the Midwest where low percent mixed/evergreen cover types were present, precipitation persisted, and minimum temperature increased. Therefore, most extrapolation risk was in southernly regions or regions with NT2 values approaching 1 (Fig. 3). 
2021-2040 SSP-2

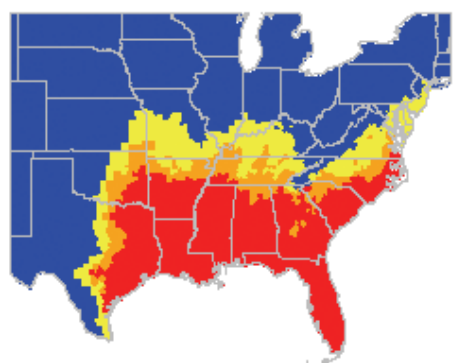

2041-2060 SSP-2

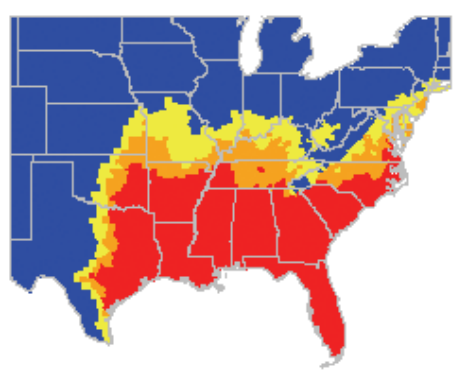

2061-2080 SSP-2

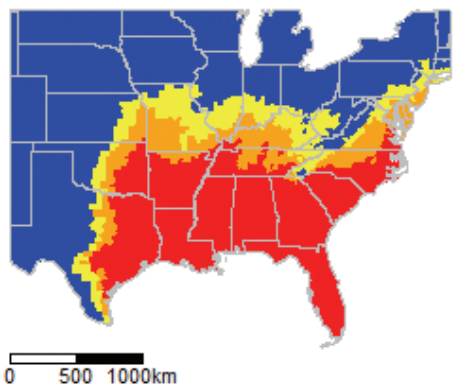

2021-2040 SSP-3

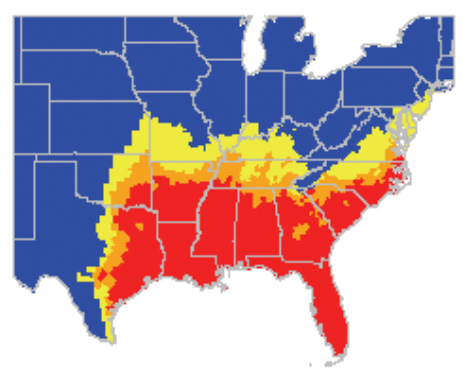

2041-2060 SSP-3

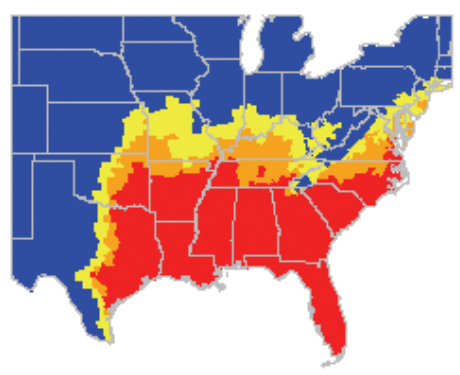

2061-2080 SSP-3

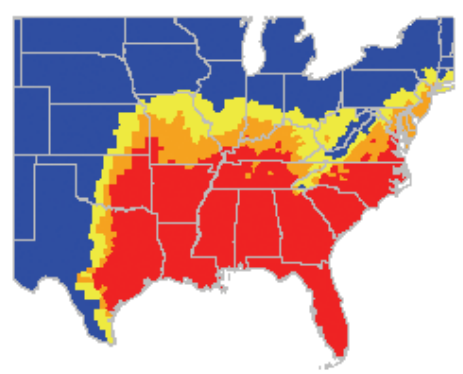

2021-2040 SSP-5

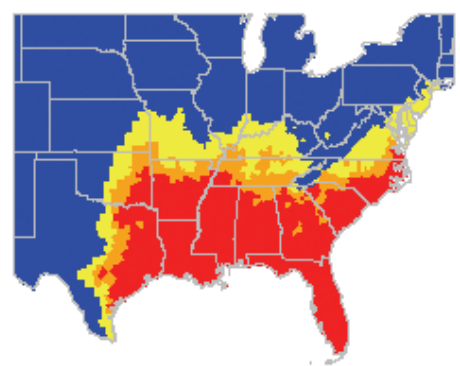

2041-2060 SSP-5

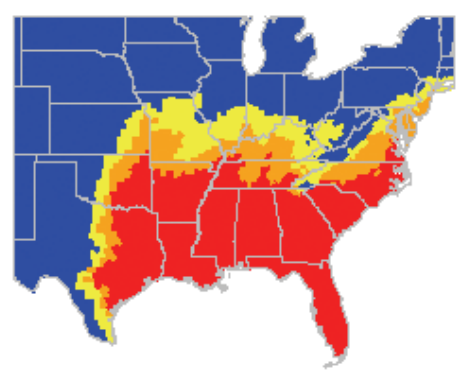

2061-2080 SSP-5

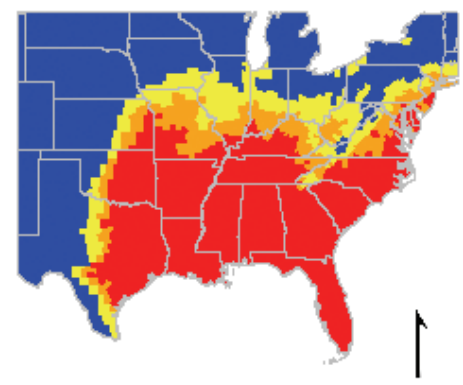

Suitability Index $\square 001 \square 2 \square{ }_{3}$

FIG. 2. Forecasted georeferenced suitability indices for L. seminolus using future climate and landscape variables and the historical L. seminolus distribution model. Suitability indices were calculated using temporally independent (2000-2019) sensitivity thresholds. SSP levels indicate increasing magnitudes of global temperature anomalies by $2100\left(\mathrm{SSP}-2=3.8-4.2^{\circ} \mathrm{C}\right.$, $\mathrm{SSP}-3=3.9-4.6^{\circ} \mathrm{C}$, and SSP-5 $=4.7-5.1^{\circ} \mathrm{C}$ )

Limiting factors (Fig. 4) of L. seminolus relative occurrence rate in various SSP future scenarios appear to generally shift from minimum temperature to percent mixed/evergreen forest cover as time and warming scenarios (SSPs) increased. In near future projections, minimum temperature as a limiting factor retracted as warming scenarios increased. This was pronounced in later years in the Midwest where minimum temperatures increased and relative occurrence rate was influenced mostly by the limited availability of mixed/evergreen cover types in that region. The same was true for the mid- and lower alluvial Mississippi Valley where large-scale row-crop agriculture and edaphic conditions naturally result in little mixed/evergreen vegetation presence on the landscape (Odom and Ford, 2020). To the west, precipitation continually appeared as a limiting factor because precipitation generally decreases from an east-to-west gradient in the continental United States. Seasonality appeared as the limiting factor in the Southeast because more influential variables contained values that resulted in a high relative occurrence rate because this region is highly suitable from the onset.

\section{DisCUSSION}

Our hypotheses were supported by our modeled results that indicated a range expansion for L. seminolus mediated by climate change with habitat 


\section{1-2040 SSP-2}

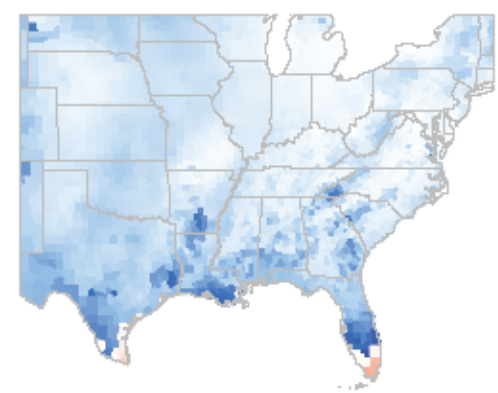

2041-2060 SSP-2

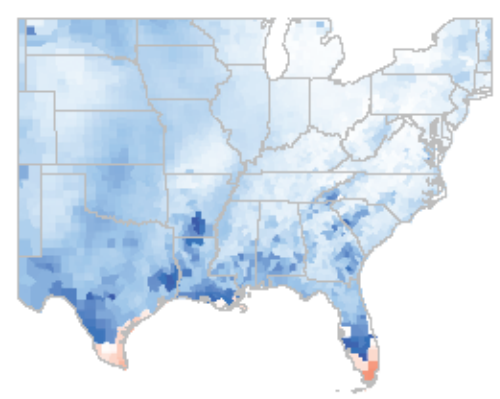

2061-2080 SSP-2

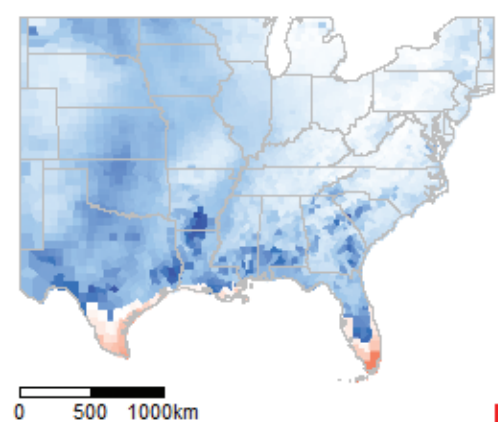

2021-2040 SSP-3

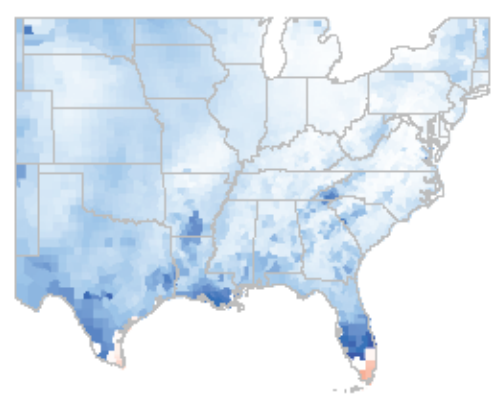

2041-2060 SSP-3

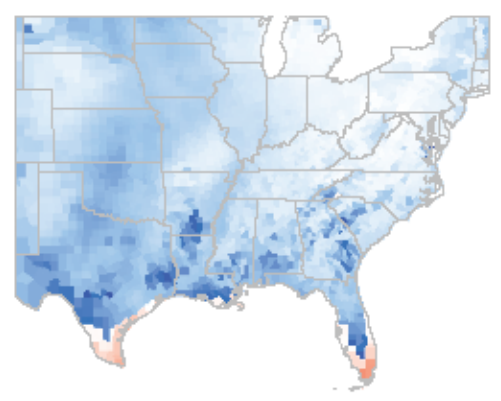

2061-2080 SSP-3
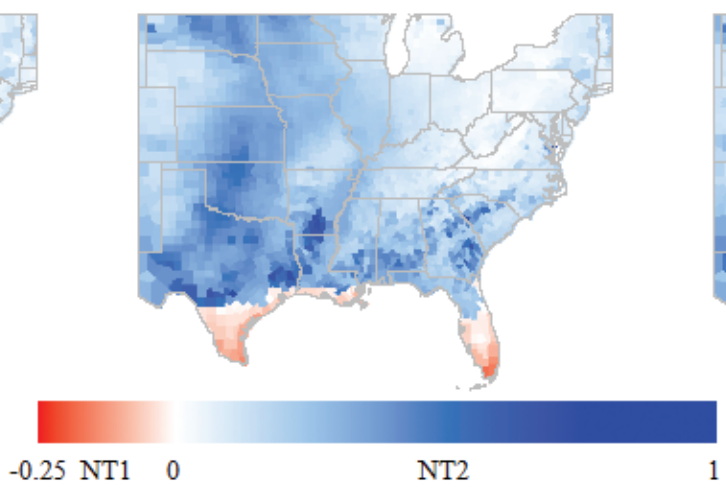

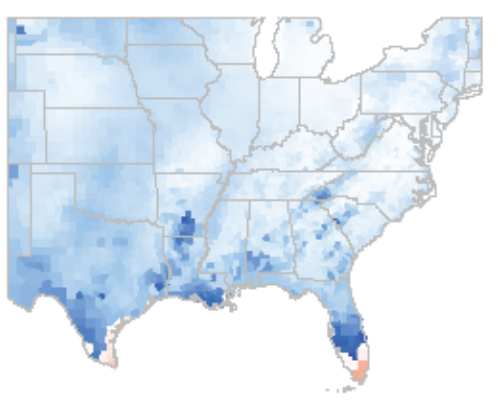

2041-2060 SSP-5

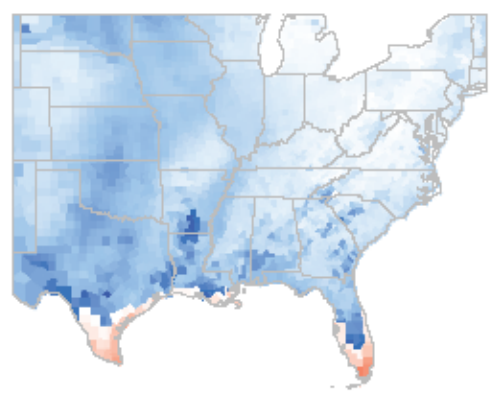

2061-2080 SSP-5

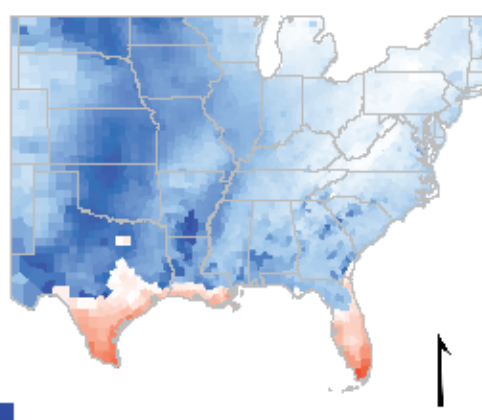

FIG. 3. Mapped NT1 and NT2 values (environmental novelty) for future distribution of $L$. seminolus using variables in future climate change scenarios. NT1 $(<0)$ values indicate single variable values outside of the training range. NT2 values $>1$ indicate unique variable value combinations. NT2 values between 0 and 1 indicate minimal, yet increasingly unique variable combinations. Darker colors indicate increased extrapolation risk

modifiers. Building on Perry (2018), our final historical (1935-1984) Maxent model showed strong positive relationships between L. seminolus occurrence and metrics of both temperature and percent mixed/evergreen forest coverage. We posit that L. seminolus distribution is mediated by these two variables, but the emphasis is on minimum temperature, as indicated by our variable contribution jackknife test. Upon model transfer to a more recent time period that included extralimital records at the time (2000-2019), we calculated a relatively high AUC ratio, indicating that the model is temporally transferable and expansion in distribution by L. seminolus is relatively predictable using this simple model structure. Our work is consistent with many other climate-mediated expansions in species distribution or poleward limit shifts (Dennis, 1993; Parmesan et al., 1999; Thomas and Lennon, 1999; Brommer, 2004; Hitch and Leberg, 2007; Massimino et al., 2015; Au and Bonebrake, 2019). Additionally, our findings provide support that bats, specifically as excellent dispersers, may serve as sentinels of climate change and display a fluid response to rapid environmental change (Jones et al., 2009; Rebelo et al., 2010; Sherwin et al., 2012; Jones and Rebelo, 2013; Razgour et al., 2016).

Although we show possible future expansion of occupiable, suitable, and highly suitable geographic 
2021-2040 SSP-2

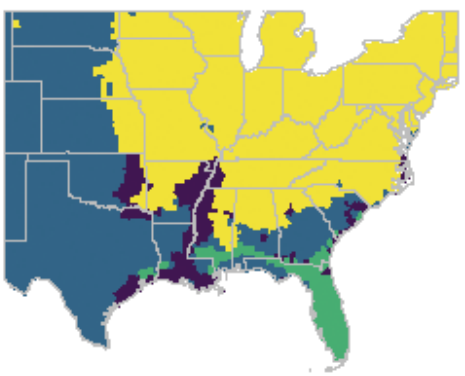

2041-2060 SSP-2

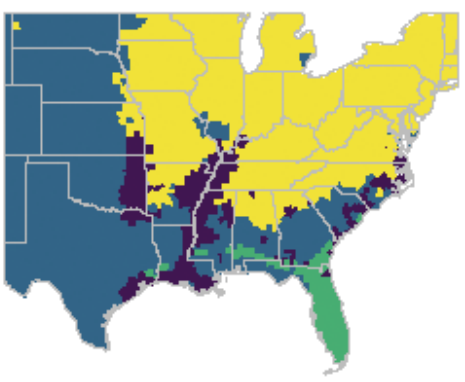

2061-2080 SSP-2

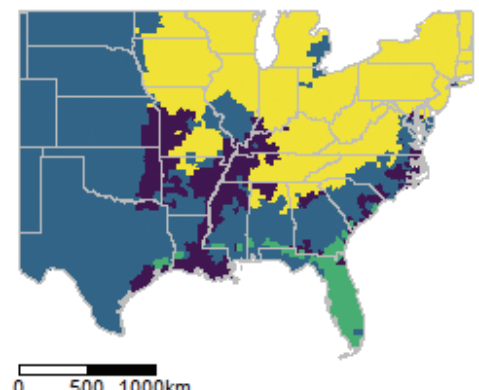

Limiting Factor
2021-2040 SSP-3

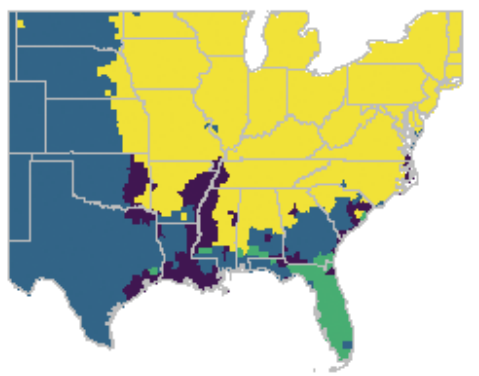

2041-2060 SSP-3

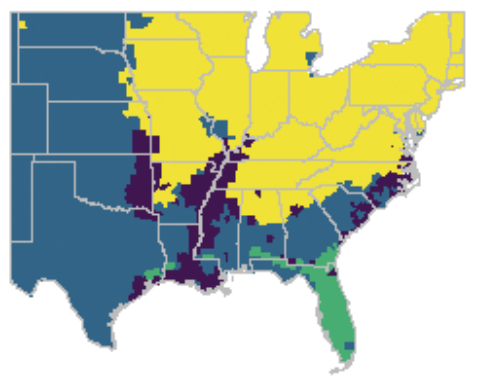

2061-2080 SSP-3

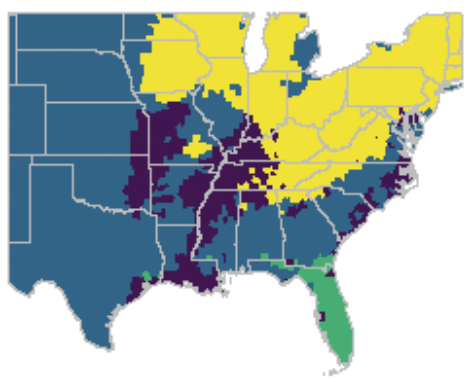

2021-2040 SSP-5

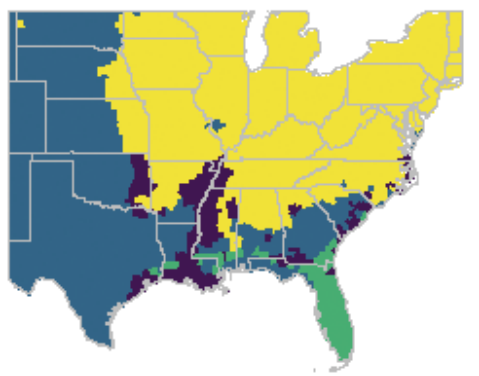

2041-2060 SSP-5

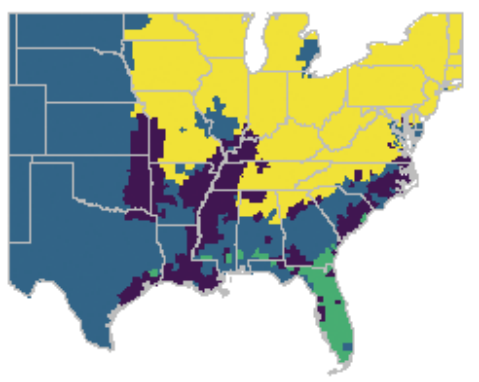

2061-2080 SSP-5

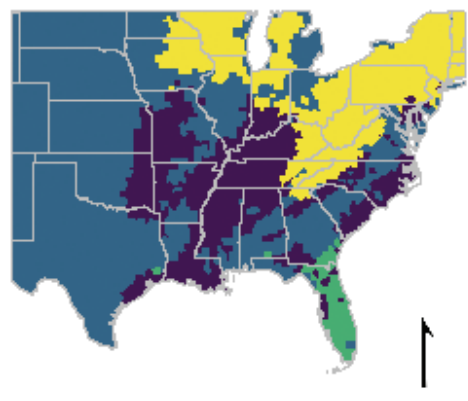

Temperuature Minimum

FIG. 4. Limiting factors on the relative occurrence rate of $L$. seminolus in future climate and landscape scenarios. Limiting factors are defined as the most influential variable in determining the relative occurrence rate (Elith 2006)

areas for L. seminolus in response to increasing minimum temperatures, we caution that projections should serve as a simple first approximation. Razgour et al. (2016) noted that extrapolating to future scenarios might be misinformative if many elements that drive species distribution are omitted such as interspecific interactions (e.g., competition), smaller scale spatial and temporal biotic needs, and dispersal. We attempted to compensate for many of these elements by incorporating day-roosting preferences as a variable and cropping the extent to reflect known dispersal ability; however, many fine-scale elements likely were obscured. First, using county as the basis of occurrence is rather course and reduces the ability to establish fine-scale variables.
Second, the reduction of cave-hibernating species since the introduction of WNS (Frick et al., 2015) may induce a competitive release allowing $L$. seminolus to occupy previously unoccupied regions, which has already been observed with other nonhibernating, migratory species (Jachowski et al., 2014). Further, extrapolation in the form of colinear shift or novel values for variables in relation to the training dataset causes uncertainty in future distribution forecasts (Elith et al., 2010; Mesgaran et al., 2014; Razgour et al., 2016). We detected minimal extrapolation risk using methods provided by Mesgaran et al. (2014). Still, some level of uncertainty exists in the southern United States, where values of temperature increased beyond the range used to 


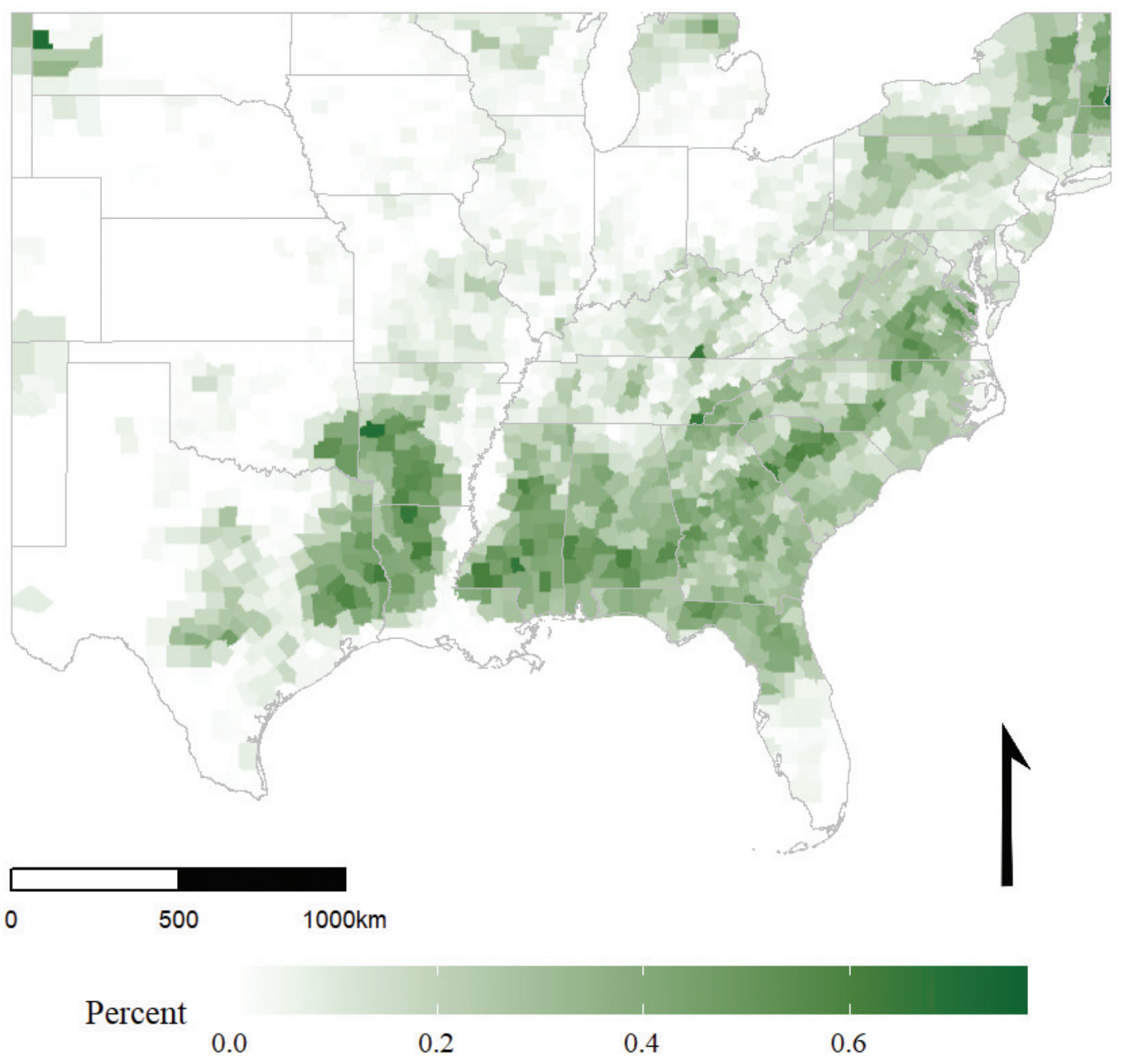

FIG 5. Percent coverage of mixed/evergreen forest in United States counties. Data is derived from the 2008 United States Geological Survey (USGS) National Land Cover Database (USGS, https://www.mrlc.gov/data/nlcd-2008-land-cover-conus, accessed 24 May, 2020)

calibrate the model. It is possible that increasing minimum active-season temperatures in parts to the Southeast may lead to contractions in distribution of Seminole bats where non-analogue temperature and habitat conditions are predicted to develop (Odom and Ford, 2020) that result in reduced environmental suitability. This phenomenon has been postulated for other bat species as well (Adams, 2010; Rebelo et al., 2010; Sherwin et al., 2012).

Although we attempted to account for seasonal effects by using a seasonality variable, our efforts in incorporating migration into the model was minimal. Lasiurus seminolus is recognized as a regional migrant (Perry, 2018) and appears to travel bi-annually from wintering to maternity areas. Within our modelling structure, our assumptions treated every county locality as 'reachable' in this first-cut approximation, an assumption that invariably should be examined further with future work. However, whereas minimum temperatures during the winter presumably dictate the wintering distribution of L. seminolus, both summer and winter temperatures are projected to increase (USGCRP, 2017). Therefore, the latitudinal limits of the wintering distribution of the species should also increase. Otherwise, if the winter distribution remains static through time, movement restrictions may still exist in future time periods and therefore, these seemingly suitable areas may be unoccupied in contrast to our forecasts. Perry (2018) documented little evidence of change in L. seminolus wintering range. However, bouts of torpor and general reduced activity at cold temperatures along with a low dormant season sampling effort make winter detection difficult (Hein et al., 2005, 2008; Jorge et al., 2020).

Plotting county records across time is subject to bias in survey effort and the influence of factors such as a warming climate in this expansion 
clearly remain speculative. For example, it is possible that L. seminolus occurred in many counties north of their apparent distribution, but simply were never detected from 1935 through 1984. Recent new county records may have resulted from increased survey efforts in the upper mid-South and lower Midwest linked to surveys for the endangered Myotis sodalis (Indiana bat), particularly following the advent of WNS. Accordingly, this may have over-inflated the recent occurrence rate relative to the entire species distribution over time. We attempted to reduce bias resulting from recent increased capture efforts by shortening the recent time interval to contain approximately equal number of positive counties; however, this violated the Maxent assumption of equal detection effort throughout geographic space across time to some degree. Regardless, moderate temporal transferability may indicate that little effort-related bias existed between the initial two time periods and that these concerns may be largely ignored at least in some regions, particularly the Midwest.

Perry (2018) initially showed less expansion of L. seminolus in regions where we forecasted expansion to be likely - primarily the mid-Atlantic coastline. On the Coastal Plain and Piedmont of Virginia, Maryland, and Delaware, both natural stands and managed pine plantations, primarily Pinus taeda (loblolly pine) occur widely, which would provide suitable day-roost habitat. The lack of L. seminolus observations in this region may be an artifact of limited capture efforts irrespective of the time period because $M$. sodalis as a regulatory driver for mist-netting efforts does not occur in those regions (however, see Germain et al. [2017]). Nevertheless, mist-netting and acoustic surveys are now underway in the region as managers have become increasingly concerned about nearshore wind energy risks to treeroosting bats (Peterson et al., 2016; Musial et al., 2019) and the need to monitor the federally threatened M. septentrionalis (Northern long-eared bat) that is present in the region (S. M. Deeley, N. J. Kalen, S. R. Freeze, E. L. Barr, and W. M. Ford, unpublished data). Recent captures of L. seminolus on the Delmarva Peninsula provide additional compelling evidence that the species occupies the region and may increase in abundance as minimum temperatures rise and Pinus spp. types remain or possibly expand.

Although most day-roost examinations of $L$. seminolus show a preference for pines, deciduous foliage use has been noted (Menzel et al., 1998; Hein et al., 2005; Perry and Thill, 2007; Perry, 2018).
Going north from the mid-South into the Midwest portions of the United States, evergreen or mixed deciduous-evergreen forest decreases substantially either as the potential natural vegetation or from forest clearing for agriculture (Fig. 5). Therefore, even with warmer minimum temperatures, L. seminolus occupancy could be limited or sporadic. However, if the roosting behavior of $L$. seminolus is more plastic than most observations suggest, these regions may be occupied as indicated in our future forecasts. Anecdotally, deciduous foliage roosting as the primary source does seem possible as outlier records were noted by Perry (2018) in western Oklahoma and southeastern Wisconsin where Pinus spp. types are relatively rare (Fig. 5; Odom and Ford, 2020).

Many survey efforts in the post-WNS environment have shifted to acoustic monitoring (E. L. Barr, A. Silvis, M. P. Armstrong, and W. M. Ford, unpublished data), particularly with regard to assessing wind-energy impacts (Arnett et al., 2008; Peterson et al., 2016; Musial et al., 2019). Lasiurus seminolus and L. borealis (Eastern red bat) emit echolocation calls that are relatively indistinguishable (Ford et al., 2006), potentially providing challenges for acoustic studies in the mid-Atlantic where the two species may or will possibly co-occur. Accordingly, efforts to provide more resolution to the biogeography of L. seminolus and/or using the species to track biotic responses to climate change will require continued mist-net survey efforts along the putative expansion zone. Nonetheless, our effort serves as a potential guide for future studies to emphasize the importance of incorporating landscape factors into species distribution modeling, if presented with historical data to validate temporal transferability, and to cautiously forecast distributions in future time periods. In general, bat-specific biogeography studies are particularly useful in a rapidly changing world. Going forward, bats may serve as a vital tool for understanding faunal responses to climate change, urbanization, and other landscape changes as bats are particularly mobile and can rapidly change locations in response to abiotic and biotic needs.

\section{SUPPLEMENTARY INFORMATION}

Contents: Supplementary Appendix S1. List and citations for the nine climate modeling groups contributing to the Coupled Model Intercomparison Project Phase 6 (CMIP6) used in this analysis. We accessed model outputs through WorldClim (https://worldclim.org/data/cmip6) at varying socio-economic pathways and year spans which were used as forecasts of temperature and precipitation in the analysis. Supplementary Information is available exclusively on BioOne. 


\section{ACKNOWLEDGEMENTS}

We thank S. Loeb and M. B. Adams for earlier reviews of this manuscript. Additionally, we thank R. Odom for miscellaneous collaborative efforts and E. A. Frimpong and S. N. Winter for statistical modeling advice. This work was supported by the Virginia Department of Wildlife Resources contracts AT-63514 and EP2489066 to Virginia Polytechnic Institute and State University Department of Fish and Wildlife Conservation Manipulation and filtering of occurrence data, manipulating and calculating environmental raster datasets, and all Maxent modeling were performed in R (R Core Team, 2019) and associated codes are available on a GitHub repository (github.com/ mtrue2/seminolebats) for reproducibility purposes. Questions about codes should be directed to the corresponding author (mtrue@vt.edu).

\section{LiTERATURE CiTED}

Abrams, M. D., and G. J. NowACKI. 2015. Exploring the early Anthropocene burning hypothesis and climate-fire anomalies for the Eastern U.S. Journal of Sustainable Forestry, 34: $30-48$.

Abrams, M. D., and G. J. Nowacki. 2019. Global change impacts on forest and fire dynamics using paleoecology and tree census data for eastern North America. Annals of Forest Science, 76: 1-23.

ADAMS, R. A. 2010. Bat reproduction declines when conditions mimic climate change projections for western North America. Ecology, 91: 2437-2445.

Ancillotto, L., L. Santini, N. Ranc, L. Maiorano, and D. Russo. 2016. Extraordinary range expansion in a common bat: the potential roles of climate change and urbanisation. Science of Nature, 103: 1-8.

Andrewartha, H. G., and L. C. BirCh. 1954. The distribution and abundance of animals. University of Chicago Press, Chicago, IL, xv $+782 \mathrm{pp}$.

Araújo, M. B., R. G. Pearson, and C. Rahbek. 2005. Equilibrium of species' distributions with climate. Ecography, 28: 693-695.

Arnett, E. B., W. K. Brown, W. P. Erickson, J. K. Fiedler, B. L. Hamilton, T. H. Henry, A. Jain, G. D. Johnson, J. Kerns, R. R. Koford, et al. 2008. Patterns of bat fatalities at wind energy facilities in North America. Journal of Wildlife Management, 72: 61-78.

Au, T. F., and T. C. Bonebrake. 2019. Increased suitability of poleward climate for a tropical butterfly (Euripus nyctelius) (Lepidoptera: Nymphalidae) accompanies its successful range expansion. Journal of Insect Science, 19: $1-8$.

Boucher, O., J. Servonnat, A. L. Albright, O. Aumont, Y. Balkanski, V. Bastrikov, S. Bekki, R. Bonnet, S. Bony, L. Bopp, et al. 2020. Presentation and evaluation of the IPSL-CM6A-LR climate model. Journal of Advances in Modeling Earth Systems, 12: e2019MS002010.

BROMMER, J. E. 2004. The range margins of northern birds shift polewards. Annales Zoologici Fennici, 41: 391-397.

Burnham, K. P., and D. R. Anderson. 2004. Multimodel inference: Understanding AIC and BIC in model selection. Sociological Methods and Research, 33: 261-304.

CARTER, T. C. 2006. Indiana bats in the Midwest: the importance of hydric habitats. Journal of Wildlife Management, 70: $1185-1190$
Collins, S. D., J. C. Аввотt, and N. E. McIntyre. 2017. Quantifying the degree of bias from using county-scale data in species distribution modeling: can increasing sample size or using county-averaged environmental data reduce distributional overprediction? Ecology and Evolution, 7: 6012-6022.

DenNis, R. L. H. 1993. Butterflies and climate change. Manchester University Press, Manchester, U.K., viii + 302 pp.

Dunne, J. P., L. W. Horowitz, A. J. Adcroft, P. Ginoux, I. M. Held, J. G. John, J. P. Krasting, S. Malyshev, V. Naik, F. PAULOT, et al. 2019. The GFDL earth system model version 4.1 (GFDL-ESM4.1): model description and simulation characteristics. Journal of Advances in Modeling Earth Systems, 11: 3167-3211.

Elith, J., M. Kearney, and S. Phillips. 2010. The art of modelling range-shifting species. Methods in Ecology and Evolution, 1: 330-342.

Elith, J., S. J. Phillips, T. Hastie, M. Dudík, Y. E. Chee, and C. J. YAtes. 2011. A statistical explanation of MaxEnt for ecologists. Diversity and Distributions, 17: 43-57.

Eyring, V., S. Bony, G. A. Meehl, C. A. Senior, B. Stevens, R. J. Stouffer, and K. E. TAYLOR. 2016. Overview of the Coupled Model Intercomparison Project Phase 6 (CMIP6) experimental design and organization. Geoscientific Model Development, 9: 1937-1958.

FIELDING, A. H., and J. F. BELl. 1997. A review of methods for the assessment of prediction errors in conservation presence/ absence models. Environmental Conservation, 24: 38-49.

Fleming, T. H. 2019. Bat migration. Pp. 605-610, in Encyclopedia of animal behavior, 2nd edition (J. C. CHOE, ed.). Academic Press, Oxford, U.K., vii + 3048 pp.

Ford, W. M., M. A. Menzel, J. L. Rodrigue, J. M. Menzel, and J. B. JoHnSON. 2005. Relating bat species presence to simple habitat measures in a central Appalachian forest. Biological Conservation, 126: 528-539.

Ford, W. M., J. M. Menzel, M. A. Menzel, J. W. Edwards, and J. C. KILGO. 2006. Presence and absence of bats across habitat scales in the upper coastal plain of South Carolina. Journal of Wildlife Management, 70: 1200-1209.

FranKLIN, J. 2009. Mapping species distributions: spatial inference and prediction. Cambridge University Press, Cambridge, U.K., xv +320 pp.

Frick, W. F., S. J. Puechmaille, J. R. Hoyt, B. A. Nickel, K. E. LAngwig, J. T. Foster, K. E. BARlow, T. BARTONiČKA, D. Feller, A. HaArsma, et al. 2015. Disease alters macroecological patterns of North American bats. Global Ecology and Biogeography, 24: 741-749.

Genoways, H. H., P. W. Freeman, and C. Grell. 2000. Extralimital records of the Mexican free-tailed bat (Tadarida brasilensis mexicana) in the central United States and their biological significance. Transactions of the Nebraska Academy of Sciences, 26: 85-96.

Germain, M. J. St., A. B. Kniowski, A. Silvis, and W. M. Ford. 2017. Who knew? First Myotis sodalis (Indiana bat) maternity colony in the coastal plain of Virginia. Northeastern Naturalist, 24: N5-N10.

GRINNELL, J. 1917. Field tests of theories concerning distributional control. American Naturalist, 51: 115-128.

Hajima, T., M. Watanabe, A. Yamamoto, H. Tatebe, M. A. Noguchi, M. Abe, R. Ohgaito, A. Ito, D. Yamazaki, H. OKAJIMA, et al. 2020. Development of the MIROC-ES2L earth system model and the evaluation of biogeochemical processes and feedbacks. Geoscientific Model Development, 13: 2197-2244. 
HANLEy, J. A., and B. J. McNeIL. 1982. The meaning and use of the area under a receiver operating characteristic (ROC) curve. Radiology, 143: 29-36.

HART, E. M., and K. BELl. 2015. prism: Download data from the Oregon prism project. R package version 0.0.6. Available at https://github.com/ropensci/prism.

Hein, C. D., S. B. Castleberry, and K. V Miller. 2005. Winter roost-site selection by Seminole bats in the Lower Coastal Plain of South Carolina. Southeastern Naturalist, 4: 473-478.

Hein, C. D., S. B. Castleberry, and K. V. Miller. 2008. Male Seminole bat winter roost-site selection in a managed forest. Journal of Wildlife Management, 72: 1756-1764.

Hijmans, R. J., S. Phillips, J. Leathwick, and J. Elith. 2020. Dismo: species distribution modeling. $\mathrm{R}$ package version 1.3-3. Available at https://rspatial.org/raster/sdm/.

Hintze, F., A. Arias-Aguilar, L. Dias-Silva, M. DelgadoJaramillo, C. R. Silva, T. JucÁ, F. L. Mischiatti, M. AlMEIDA, B. BEzERra, L. M. S. Aguiar, et al. 2019. Molossid unlimited: extraordinary extension of range and unusual vocalization patterns of the bat, Promops centralis. Journal of Mammalogy, 101: 417-432.

Hitch, A. T., and P. L. LeBERG. 2007. Breeding distributions of North American bird species moving north as a result of climate change. Conservation Biology, 21: 534-539.

Huang, J., E. A. Frimpong, and D. J. Orth. 2016. Temporal transferability of stream fish distribution models: can uncalibrated SDMs predict distribution shifts over time? Diversity and Distributions, 22: 651-662.

Jachowski, D. S., C. A. Dobony, L. S. Coleman, W. M. Ford, E. R. BritzKe, and J. L. Rodrigue. 2014. Disease and community structure: white-nose syndrome alters spatial and temporal niche partitioning in sympatric bat species. Diversity and Distributions, 20: 1002-1015.

Jones, G., and H. ReBelo. 2013. Responses of bats to climate change: learning from the past and predicting the future. Pp. 457-478, in Bat evolution, ecology, and conservation (R. A. Adams and S. C. Pedersen, eds.). Springer, New York, NY, $547 \mathrm{pp}$.

Jones, G., D. Jacobs, T. Kunz, M. Willig, and P. Racey. 2009. Carpe noctem: the importance of bats as bioindicators. Endangered Species Research, 8: 93-115.

Jorge, M., S. R. Freeze, S. E. Sweeten, M. C. True, H. Taylor, K. M. Gorman, M. S. Germain, E. P. Garrison, and M. J. CHERRY. 2020. Dormant season burning impacts to migratory bats. United States Department of Defence Legacy Program Final Report HQ0034-18-2-0012, Arlington, VA, $65 \mathrm{pp}$.

LACKI, M. J., J. J. KRUPA, and S. P. LACKI. 2014. Extralimital movement of Seminole bats (Lasiurus seminolus) into Kentucky. Journal of the Kentucky Academy of Science, 75: 80-84.

Lorch, J. M., C. U. Meteyer, M. J. Behr, J. G. Boyles, P. M. Cryan, A. C. Hicks, A. E. Ballmann, J. T. H. Coleman, D. N. RedeLl, D. M. ReEDER, et al. 2011. Experimental infection of bats with Geomyces destructans causes white-nose syndrome. Nature, 480: 376-378.

Lundy, M., I. MontgOMERY, and J. Russ. 2010. Climate changelinked range expansion of Nathusius' pipistrelle bat, Pipistrellus nathusii. Journal of Biogeography, 37: 2232-2242.

LYMAN, C. P. 1970. Thermoregulation and metabolism in bats. Pp. 301-330, in Biology of bats. Volume 1 (W. A. WIMSATT, ed.). Academic Press, New York, NY, 406 pp.

Massimino, D., A. Johnston, and J. W. Pearce-Higgins. 2015.
The geographical range of British birds expands during 15 years of warming. Bird Study, 62: 523-534.

Mcallister, C. T., Z. D. Ramsey, N. E. Solley, C. T. McallisTER, and Z. D. RAMSEY. 2004. Noteworthy records of the Seminole bat, Lasiurus seminolus (Chiroptera: Vespertilionidae), from southwestern Arkansas and northeastern Arkansas. Journal of the Arkansas Academy of Science, 58: 25 .

McCracken, G. F., R. F. Bernard, M. Gamba-Rios, R. Wolfe, J. J. Krauel, D. N. Jones, A. L. Russell, and V. A. Brown. 2018. Rapid range expansion of the Brazilian free-tailed bat in the southeastern United States, 2008-2016. Journal of Mammalogy, 99: 312-320.

Menzel, M. A., T. C. Carter, B. R. Chapman, and J. Laerm. 1998. Quantitative comparison of tree roosts used by red bats (Lasiurus borealis) and Seminole bats (L. seminolus). Canadian Journal of Zoology, 76: 630-634.

Menzel, M. A., D. M. Krishon, T. C. Carter, and J. Laerm. 1999. Notes on tree roost characteristics of the northern yellow bat (Lasiurus intermedius), the Seminole bat (L. seminolus), the evening bat (Nycticeius humeralis), and the eastern pipistrelle (Pipistrellus subflavus). Florida Scientist, 62: 185-193.

Menzel, M. A., T. C. Carter, W. M. Ford, B. R. Chapman, and J. OzIER. 2000. Summer roost tree selection by eastern red, Seminole, and evening bats in the upper coastal plain of South Carolina. Proceedings of Annual Conference of Southeastern Association of Fish and Wildlife Agencies, 54: 304-313.

Merow, C., M. J. Smith, and J. A. Silander. 2013. A practical guide to MaxEnt for modeling species' distributions: What it does, and why inputs and settings matter. Ecography, 36: 1058-1069.

Mesgaran, M. B., R. D. Cousens, and B. L. Webber. 2014. Here be dragons: A tool for quantifying novelty due to covariate range and correlation change when projecting species distribution models. Diversity and Distributions, 20: 1147-1159.

Muscarella, R., P. J. Galante, M. Soley Guardia, R. A. Boria, J. M. Kass, M. Uriarte, and R. P. ANDERSON. 2014 ENMeval: an R package for conducting spatially independent evaluations and estimating optimal model complexity for Maxent ecological niche models. Methods in Ecology and Evolution, 5: 1198-1205.

Musial, W. D., P. C. Beiter, P. Spitsen, J. Nunemaker, and V. GEVORGIAN. 2019. 2018 Offshore wind technologies market report. U.S. Department of Energy, Oak Ridge, 76 pp.

Nakićenović, N., J. Alcamo, G. Davis, B. De Vries, J. Fenhann, S. Gaffin, K. Gregory, A. Gritbler, T. Y. Jung, T. KRAM, et al. 2000. Special report on emissions scenarios (SRES). A Special Report of Working Group III of the Intergovernmental Panel on Climate Change. Cambridge University Press, Cambridge, U.K., 599 pp.

ODOM, R. H., and W. M. ForD. 2020. Assessing the vulnerability of military installations in the coterminous United States to potential biome shifts resulting from rapid climate change. Environmental Management, 66: 564-589.

OMmundsen, P., C. Lausen, and L. Matthias. 2017. First acoustic records of the Brazilian free-tailed bat (Tadarida brasiliensis) in British Columbia. Northwestern Naturalist, 98: 132-136.

O’Neill, B. C., E. Kriegler, K. Riahi, K. L. Ebi, S. Hallegatte, T. R. Carter, R. Mathur and D. P. van Vuuren. 
2014. A new scenario framework for climate change research: the concept of shared socioeconomic pathways. Climatic Change, 122: 387-400.

PARMesan, C. 2006. Ecological and evolutionary responses to recent climate change. Annual Review of Ecology, Evolution, and Systematics, 37: 637-669.

Parmesan, C., N. Ryrholm, C. Stefanescu, J. K. Hill, C. D. Thomas, H. Descimon, B. Huntley, L. Kaila, J. KullBERG, and T. TAMMARU. 1999. Poleward shifts in geographical ranges of butterfly species associated with regional warming. Nature, 399: 579-583.

PERRY, R. W. 2018. Migration and recent range expansion of Seminole bats (Lasiurus seminolus) in the United States. Journal of Mammalogy, 99: 1478-1485.

Perry, R. W., and R. E. ThiLl. 2007. Summer roosting by adult male Seminole bats in the Ouachita Mountains, Arkansas. American Midland Naturalist, 158: 361-368.

Peterson, A. T. 2011. Ecological niches and geographic distributions. Princeton University Press, Princeton, N.J., 328 pp.

Peterson, A. T., M. Papeş, and J. Soberón. 2008. Rethinking receiver operating characteristic analysis applications in ecological niche modeling. Ecological Modelling, 213: 63-72.

Peterson, T., S. Pelletier, and M. Giovanni. 2016. Long-term bat monitoring on islands, offshore structures, and coastal sites in the gulf of Maine, mid-Atlantic, and Great Lakes final report. Topsham, M.E.

Phillips, S. J., R. P. Anderson, and R. E. Schapire. 2006. Maximum entropy modeling of species geographic distributions. Ecological modelling, 190: 231-259.

Randin, C. F., T. Dirnböck, S. Dullinger, N. E. Zimmermann, M. ZAPPA, and A. GUISAN. 2006. Are niche-based species distribution models transferable in space? Journal of Biogeography, 33: 1689-1703.

Razgour, O., H. Rebelo, M. Di Febbraro, and D. Russo. 2016. Painting maps with bats: Species distribution modelling in bat research and conservation. Hystrix, 27: 30-37.

R Core Team. 2019. R: A language and environment for statistical computing. R Foundation for Statistical Computing. Vienna, Austria. Available at www.r-project.org.

Rebelo, H., P. Tarroso, and G. Jones. 2010. Predicted impact of climate change on european bats in relation to their biogeographic patterns. Global Change Biology, 16: 561-576.

Sachanowicz, K., A. Wower, and A. T. Bashta. 2006. Further range extension of Pipistrellus kuhlii (Kuhl, 1817) in central and eastern Europe. Acta Chiropterologica, 8: 543-548.

Séférian, R., P. Nabat, M. Michou, D. Saint-Martin, A. Voldoire, J. Colin, B. Decharme, C. Delire, S. Berthet, M. Chevallier, et al. 2019. Evaluation of CNRM earth system model, CNRM-ESM2-1: role of earth system processes in present-day and future climate. Journal of Advances in Modeling Earth Systems, 11: 4182-4227.

Sherwin, H. A., W. I. Montgomery, and M. G. Lundy. 2012. The impact and implications of climate change for bats. Mammal Review, 43: 171-182.

Sohl, T. L., K. L. SAyler, M. A. Bouchard, R. R. Reker, A. M. Friesz, S. L. Bennett, B. M. Sleeter, R. R. Sleeter, T. WILSON, C. Soulard, et al. 2014. Spatially explicit modeling of 1992-2100 land cover and forest stand age for the conterminous United States. Ecological Applications, 24: $1015-1036$.

Sohl, T., R. Reker, M. Bouchard, K. SAyler, J. Dornbierer, S. WiKA, R. QuenZER and A. Friesz. 2016. Modeled historical land use and land cover for the conterminous United States. Journal of Land Use Science, 11: 476-499.

Swart, N. C., J. N. S. Cole, V.V. Kharin, M. Lazare, J. F. Scinocca, N. P. Gillett, J. Anstey, V. Arora, J. R. ChrisTIAN, S. HANNA, et al. 2019. The Canadian earth system model version 5 (CanESM5.0.3). Geoscientific Model Development, 12: 4823-4873.

Tatebe, H., T. Ogura, T. Nitta, Y. Komuro, K. Ogochi, T. Takemura, K. Sudo, M. Sekiguchi, M. Abe, F. Saito, et al. 2019. Description and basic evaluation of simulated mean state, internal variability, and climate sensitivity in MIROC6. Geoscientific Model Development, 12: 2727-2765.

Thomas, C. D., and J. J. Lennon. 1999. Birds extend their ranges northwards. Nature, 399: 213.

USGCRP. 2017. Temperature changes in the United States. Pp. 185-206, in Climate Science Special Report: Fourth National Climate Assessment, Volume I (D. J. WuebBLEs, D. W. Fahey, K. A. Hibbard, D. J. Dokken, B. C. Stewart, and T. K. MAYCOCK, eds.). United States Global Change Research Program, Washington, D.C., 470 pp.

van Vuuren, D. P., J. Edmonds, M. Kainuma, K. Riahi, A. Thomson, K. Hibbard, G. C. Hurtt, T. Kram, V. Krey, J.-F. LAMARQUE, et al. 2011. The representative concentration pathways: an overview. Climatic Change, 109: 5-31.

Voldoire, A., D. Saint-Martin, S. SÉnési, B. Decharme, A. Alias, M. Chevallier, J. Colin J. F. Guérémy, M. Michou, M. P. MoINE, et al. 2019. Evaluation of CMIP6 DECK experiments with CNRM-CM6-1. Journal of Advances in Modeling Earth Systems, 11: 2177-2213.

Warren, D. L., and S. N. SEIFERT. 2011. Ecological niche modeling in Maxent: The importance of model complexity and the performance of model selection criteria. Ecological Applications, 21: 335-342.

Wu, J. 2016. Detection and attribution of the effects of climate change on bat distributions over the last 50 years. Climatic Change, 134: 681-696.

Wu, T., Y. Lu, Y. Fang, X. Xin, L. Li, W. Li, W. Jie, J. Zhang, Y. LiU, L. Zhang, et al. 2019. The Beijing Climate Center climate system model (BCC-CSM): the main progress from CMIP5 to CMIP6. Geoscientific Model Development, 12: $1573-1600$.

Yang, L., S. Jin, P. Danielson, C. Homer, L. Gass, S. M. Bender, A. Case, C. Costello, J. Dewitz, J. Fry, M. FunK, et al. 2018. A new generation of the United States National Land Cover Database: requirements, research priorities, design, and implementation strategies. ISPRS Journal of Photogrammetry and Remote Sensing, 146: 108-123.

Yukimoto, S., H. Kawai, T. Koshiro, N. Oshima, K. Yoshida, S. Urakawa, H. Tsujino, M. Deushi, T. Tanaka, M. HosaKA, et al. 2019. The meteorological research institute earth system model version 2.0, MRI-ESM2.0: description and basic evaluation of the physical component. Journal of the Meteorological Society of Japan, 97: 931-965. 